\title{
Estudo da biodegradabilidade de fluoroquinolona por meio da utilização de biomassas aeróbias e anaeróbias
}

\author{
Study of fluoroquinolone biodegradability by using aerobic and anaerobic biomass

\begin{abstract}
Lucilaine Valéria de Souza Santos ${ }^{1,2 *} \odot$, Raquel Sampaio Jacob ${ }^{1,2}$, Lisete Celina Lange',
\end{abstract} \\ Victor Rezende Moreira, ${ }^{1,2}$, Yuri Abner Rocha Lebron ${ }^{1,2}$, Míriam Cristina Santos do Amaral'
}

\begin{abstract}
口
RESUMO

Os antibióticos como o norfloxacino constituem os fármacos mais utilizados na Medicina, com consumos expressivos no mundo todo. Por ser quimicamente estável, após sua administração a maior parte do fármaco é excretada de forma inalterada e, geralmente, é removida apenas parcialmente nas estações de tratamento de esgoto (ETES). Assim, o presente trabalho buscou avaliar a eficiência dos processos biológicos na remediação de norfloxacino investigando os mecanismos de remoção envolvidos. O objetivo foi verificar a biodegradabilidade do fármaco e sua toxicidade. Para realização dos ensaios de biodegradabilidade, coletaram-se lodos na ETE Arrudas (Sabará, Minas Gerais) dos processos de tratamento com lodos ativados, reatores upflow anaerobic sludge blanket (UASB) e biodigestor anaeróbio. Reatores em escala de bancada foram montados com lodo aclimatado e não aclimatado. Amostras tiveram a biodegradabilidade acompanhada por meio da determinação do carbono orgânico total e da absortividade molar do norfloxacino por espectrofotometria de UVNis. Determinou-se a toxicidade por intermédio de ensaios com a bactéria Aliivibrio fischeri. Entre as biomassas utilizadas, a mais eficiente na remoção do norfloxacino foi advinda dos reatores UASB (23\%), seguida do biodigestor anaeróbio (18\%) e, então, dos lodos ativados (13\%). Quanto à ecotoxicidade, a degradação anaeróbia promoveu a eliminação da toxicidade do antibiótico, enquanto com relação à degradação aeróbia os efluentes gerados permanecem tóxicos.
\end{abstract}

Palavras-chave: fármacos; estações de tratamento de esgoto; tratamento biológico; ecotoxicidade.

\begin{abstract}
Antibiotics, such as norfloxacin, are the most widely used drugs in medicine, with significant consumption in the world. By being chemically stable, most of the drug is excreted unchanged after administration, and is generally only partially removed in the sewage treatment plants (STPS). Thus, the efficiency of biological processes in the remediation of norfloxacin was investigated by the present work, verifying the removal mechanisms involved. Its objective was to verify the drug's biodegradability and toxicity. In order to perform biodegradability tests, sludges were collected in Arrudas STP (Sabara, Minas Gerais) from the treatment processes with activated sludge, upflow anaerobic sludge blanket (UASB) reactors and anaerobic biodigester. Bench-scale reactors were assembled with acclimatized and non-acclimatized sludge. Samples had their biodegradability monitored by determination of total organic carbon and norfloxacin molar absorptivity by UV/Vis spectrophotometry. The toxicity was determined by tests with Aliivibrio fischeri. Among the used biomass, UASB reactors was the most efficient in removing norfloxacin (23\%), followed by anaerobic biodigester (18\%), and activated sludge (13\%). Regarding ecotoxicity, the anaerobic degradation promoted the elimination of antibiotic toxicity, while with aerobic degradation, the effluents generated remained toxic.
\end{abstract}

Keywords: pharmaceuticals; sewage treatment plants; biological treatment; ecotoxicity.

\section{INTRODUÇÃO}

Compostos farmacêuticos incluem anti-inflamatórios, antipiréticos, analgésicos, reguladores lipídicos, antibióticos, antidepressivos, agentes quimioterápicos, contraceptivos e outros mais. O consumo global de medicamentos em 2020 deve atingir
4,5 trilhões de doses, representando aumento de $24 \%$ em relação a 2015. Esses valores variam de acordo com o nível de desenvolvimento econômico do país, e os países em desenvolvimento são os maiores contribuintes para esse crescimento (IMSI, 2015). Os antibióticos constituem um caso especial, isso porque 
correspondem à maior categoria de fármacos utilizados na medicina humana e veterinária.

Especificamente o norfloxacino, antibiótico da família das fluoroquinolonas, tem extensivas aplicações e é considerado importante arma no combate a organismos gram-negativos e gram-positivos, e as últimas gerações desses agentes antimicrobianos chegam a ser ativas até contra bactérias anaeróbias (SILVA et al., 2011).

Lindberg et al. (2005) relataram que as fluoroquinolonas são os antibióticos mais frequentemente detectados em efluentes e que na maioria das vezes estão acima do limite de quantificação. Em estudo realizado por Botero-Coy et al. (2018), verificou-se, em sete estações de tratamento de água (ETAs), que a concentração de norfloxacino variou de 0,98 a $2,01 \mu \mathrm{g} \cdot \mathrm{L}^{-1}$. A presença dos citados compostos em água de abastecimento humano se deve ao fato de serem quimicamente estáveis. Contribui também o fato de que, após a administração em humanos e animas, mais de $90 \%$ do fármaco pode ser excretado de forma inalterada (HIRSCH et al., 1999; LÓPEZ-SERNA et al., 2013). A situação agrava-se diante dos resultados fornecidos por diversas pesquisas que esclarecem que alguns fármacos, a exemplo dos antibióticos, são removidos apenas parcialmente nas estações de tratamento de esgoto (ETEs) (MUTIYAR \& MITTAL, 2014), sendo detectados, em variadas concentrações, mesmo após a etapa de tratamento empregada (DINH et al., 2017; SUN et al., 2016; PAPAGEORGIOU; KOSMA; LAMBROPOULOU, 2016). A informação de que a presença de antibióticos é capaz de causar resistência bacteriana adicionou uma nova perspectiva nas avaliações de risco relacionadas à presença desses compostos no meio ambiente (MIDDLETON; SALIERNO, 2013; SHAH et al., 2012), trazendo a possibilidade de que procedimentos médicos comuns, anteriormente consagrados, sejam ineficazes (OMS, 2000).

Os processos biológicos para o tratamento de compostos farmacêuticos têm recebido atenção especial nas últimas décadas. Sabe-se que, uma vez nas estações de tratamento, os citados compostos e seus metabólitos somente serão degradados completamente se forem biodegradáveis e se houver um outro substrato disponível para a multiplicação microbiana (LAJEUNESSE et al., 2012). Em vista da relevância do tratamento biológico de efluentes, em função de sua ampla utilização, o presente estudo teve por objetivo avaliar a eficiência dos processos biológicos aeróbio e anaeróbio na remediação de norfloxacino, investigando os mecanismos de remoção envolvidos. Paralelamente a este estudo foram realizados ensaios ecotoxicológicos, utilizando a bactéria marinha luminescente Alivibrio fischeri, nos efluentes bruto e tratado. A verificação da toxicidade dos efluentes tratados torna-se uma etapa importante por causa da possibilidade formação de compostos intermediários tóxicos durante as etapas de tratamento (URBANCZYC, 2007).

\section{METODOLOGIA}

\section{Reagentes}

O norfloxacino utilizado foi adquirido dos laboratórios USP e tem grau de pureza $\geq 99,5 \%$. A solução do fármaco foi preparada em água Milli-Q a uma concentração de $15 \mathrm{mg} \cdot \mathrm{L}^{-1}$.

Outros químicos utilizados para o desenvolvimento dessa pesquisa, citados à frente, foram adquiridos de Merck (Alemanha), Carlo Erba (Itália), Fluka e SDI (Estados Unidos), sendo selecionados os de maior pureza disponível.

\section{Amostragem e aclimatação da biomassa}

As diferentes biomassas utilizadas nas montagens dos reatores de biodegradabilidade foram coletadas na ETE Arrudas (1953'46.8”'S, 4352’40.8”W), localizada na região de Sabará, Minas Gerais. Foram coletadas biomassas referentes aos processos de tratamento com lodos ativados, reatores upflow anaerobic sludge blanket (UASB) e biodigestor anaeróbio.

Cada biomassa coletada foi aclimatada por aproximadamente nove semanas, recebendo carga crescente do antibiótico e decrescente de solução de glicose e nutrientes.

Para aclimatação da biomassa aeróbia, foram montados reatores de $2 \mathrm{~L}$ utilizando $1.000 \mathrm{~mL}$ de lodo aeróbio devidamente lavado com água deionizada, $600 \mathrm{~mL}$ de solução de antibiótico/glicose e $2 \mathrm{~mL}$ de soluções de nutrientes $\left(\mathrm{CaCl}_{2}, \mathrm{FeCl}_{3} \cdot 7 \mathrm{H}_{2} \mathrm{O}, \mathrm{MgSO}_{4}\right.$ e tampão fosfato) preparadas em conformidade com método de demanda biológica de oxigênio - DBO (APHA, 2012). Promoveu-se aeração nos reatores utilizando aeradores de laboratório e acertou-se o pH para 7.

Já para aclimatação da biomassa anaeróbia foram montados reatores de $2 \mathrm{~L}$ utilizando $1.000 \mathrm{~mL}$ de cada lodo anaeróbio (UASB e biodigestor anaeróbio) devidamente lavado com água deionizada, $600 \mathrm{~mL}$ de solução de antibiótico/glicose e $200 \mathrm{~mL}$ de solução preparada a partir das soluções de macro e micronutrientes (Tabela 1). Para o preparo da última, utilizaram-se $2 \mathrm{~mL}$ da solução de micronutrientes e $200 \mathrm{~mL}$ da solução de macronutrientes. Essas quantidades foram transferidas para balão de $1 \mathrm{~L}$, que teve seu volume completado com água deionizada.

\section{Descrição dos ensaios de biodegradabilidade aeróbia}

Para avaliação da biodegradabilidade aeróbia, foram montados reatores a partir de uma adaptação da metodologia proposta por ZahnWellens (apud OECD, 1995).

Os ensaios de degradação biológica aeróbia foram realizados empregando reatores de 1,5 L contendo biomassa aclimatada ou não na concentração de $0,5 \mathrm{~g} \cdot \mathrm{L}^{-1}$ de sólidos voláteis.

Em cada reator foram adicionados $1,5 \mathrm{~mL}$ de soluções de nutrientes $\left(\mathrm{CaCl}_{2}, \mathrm{FeCl}_{3} \cdot 7 \mathrm{H}_{2} \mathrm{O}, \mathrm{MgSO}_{4}\right.$ e tampão fosfato $)$ preparadas em 
conformidade com método de DBO (APHA, 2012), lodo aeróbio aclimatado ou não (devidamente lavado com água deionizada), solução contendo o antibiótico em estudo e glicose. Nos reatores denominados de brancos a única fonte de carbono disponível foi a glicose em concentração de $500 \mathrm{mg} \cdot \mathrm{L}^{-1}$.

Salienta-se que o experimento foi divido em duas etapas: a primeira delas com lodo não aclimatado e a segunda com lodo aclimatado. Promoveu-se aeração nos reatores utilizando aeradores de laboratório.

\section{Descrição dos ensaios de biodegradabilidade anaeróbia}

Para avaliação da biodegradabilidade anaeróbia, foram montados reatores a partir de uma adaptação da metodologia proposta por Field, Sierra e Letting (1988).

Tabela 1 - Composição das soluções de macro e micronutrientes.

\begin{tabular}{|c|c|c|}
\hline Solução & Reagentes & Concentração (g. $\left.\mathbf{L}^{-1}\right)$ \\
\hline \multirow{6}{*}{ Macronutrientes } & $\mathrm{KH}_{2} \mathrm{PO}_{4}$ & 1,50 \\
\hline & $\mathrm{K}_{2} \mathrm{HPO}_{4}$ & 6,50 \\
\hline & $\mathrm{NH}_{4} \mathrm{Cl}$ & 5,00 \\
\hline & $\mathrm{Na}_{2} \mathrm{~S} \cdot 9 \mathrm{H}_{2} \mathrm{O}$ & 0,50 \\
\hline & $\mathrm{CaCl}_{2} \cdot 2 \mathrm{H}_{2} \mathrm{O}$ & 1,00 \\
\hline & $\mathrm{MgCl}_{2} \cdot 6 \mathrm{H}_{2} \mathrm{O}$ & 1,00 \\
\hline \multirow{10}{*}{ Micronutrientes } & $\mathrm{FeCl}_{3} \cdot \mathrm{H}_{2} \mathrm{O}$ & 2,00 \\
\hline & $\mathrm{ZnCl}_{2}$ & 0,05 \\
\hline & $\mathrm{CuCl}_{2} \cdot 2 \mathrm{H}_{2} \mathrm{O}$ & 0,03 \\
\hline & $\mathrm{MnCl}_{2} \cdot 4 \mathrm{H}_{2} \mathrm{O}$ & 0,50 \\
\hline & $\left(\mathrm{NH}_{4}\right)_{6} \mathrm{MO}_{7} \mathrm{O}_{24} \cdot \mathrm{H}_{2} \mathrm{O}$ & 0,05 \\
\hline & $\mathrm{NiCl}_{2} \cdot 6 \mathrm{H}_{2} \mathrm{O}$ & 0,05 \\
\hline & $\mathrm{AlCl}_{3}$ & 0,05 \\
\hline & $\mathrm{CaCl}_{2} \cdot 6 \mathrm{H}_{2} \mathrm{O}$ & 2,00 \\
\hline & $\mathrm{H}_{3} \mathrm{BO}_{4}$ & 0,01 \\
\hline & $\mathrm{HCl}$ & $1 \mathrm{~mL}$ \\
\hline
\end{tabular}

Em cada reator montado foram adicionados $200 \mathrm{~mL}$ de solução de macronutrientes/micronutrientes (Tabela 1), lodo anaeróbio aclimatado ou não, solução contendo o antibiótico em estudo e glicose.

Da mesma forma que na biodegradabilidade aeróbia, nos reatores brancos a glicose foi a única fonte de carbono. Para os reatores anaeróbios, novamente o experimento foi divido em duas etapas: a primeira delas com lodo não aclimatado e a segunda com lodo aclimatado a uma concentração de $0,5 \mathrm{mg} \cdot \mathrm{L}^{-1}$ de sólidos voláteis.

Resumidamente, as condições operacionais adotadas para os testes de biodegradabilidade aeróbia e anaeróbia foram sintetizadas na Tabela 2. Todos os ensaios realizados ao longo do estudo foram realizados em triplicata, sendo os valores apresentados correspondentes à média dos dados obtidos

\section{Medição e acompanhamento do norfloxacino}

Para o monitoramento do norfloxacino, foram utilizados espectrofotômetro UV/Vis Perkin Elmer, Lambda XL, e curva de calibração externa. Para avaliação da mineralização do antibiótico, utilizou-se analisador de carbono orgânico total (COT), marca Shimadzu, modelo TOC- $\mathrm{V}_{\mathrm{CPN}}$, com amostrador automático ASI-V.

As alíquotas coletadas foram filtradas em membranas de $0,45 \mu \mathrm{m}$ em PVDF hidrofílico e analisadas imediatamente após a coleta. Determinou-se a absortividade molar em $273 \mathrm{~nm}$ e a taxa de mineralização por meio da medida do COT. Uma varredura do espectro de absorção do norfloxacino revelou três picos distintos de absorção, e o máximo de absorção foi em 273 nm (Figura 1), motivo pelo qual esse comprimento de onda foi escolhido para a quantificação do norfloxacino.

\section{Ensaios ecotoxicológicos}

As amostras resultantes dos reatores de biodegradabilidade aeróbia e anaeróbia tiveram sua ecotoxicidade determinada por meio da realização de ensaios ecotoxicológicos com a bactéria marinha luminescente Alivibrio fischeri, utilizando o equipamento MICROTOX; Modelo 500 Analyzer (SDI).

Tabela 2-Resumo das principais condições analíticas utilizadas para os testes de biodegradabilidade aeróbia e anaeróbia utilizando o antibiótico norfloxacino.

\begin{tabular}{|c|c|c|c|c|c|c|}
\hline \multirow[b]{2}{*}{ Processos utilizados } & \multicolumn{3}{|c|}{ Processos biológicos sem aclimatação } & \multicolumn{3}{|c|}{ Processos biológicos aclimatados } \\
\hline & Lodos ativados & UASB & $\begin{array}{l}\text { Biodigestores } \\
\text { anaeróbios }\end{array}$ & Lodos ativados & UASB & $\begin{array}{c}\text { Biodigestores } \\
\text { anaeróbios }\end{array}$ \\
\hline Concentração inicial (mg. $\left.L^{-1}\right)$ & 4,1 & 2,7 & 4,8 & 2,5 & 1,9 & 2,0 \\
\hline Concentração final $\left(m g \cdot L^{-1}\right)$ & 3,6 & 2,1 & 3,9 & 3,4 & 1,7 & 2,6 \\
\hline Concentração de glicose $\left(\mathrm{mg} \cdot \mathrm{L}^{-1}\right)$ & \multicolumn{6}{|c|}{465} \\
\hline Temperatura $\left({ }^{\circ} \mathrm{C}\right)$ & \multicolumn{6}{|c|}{29} \\
\hline Tempo (dias) & \multicolumn{6}{|c|}{30} \\
\hline $\mathrm{pH}$ & \multicolumn{6}{|c|}{7} \\
\hline
\end{tabular}

UASB: upflow anaerobic sludge blanket. 
Todas as amostras obtidas durante a pesquisa, tanto a solução bruta de norfloxacino quanto as amostras provenientes dos reatores usados, passaram pelo ensaio, para avaliação da biodegradabilidade aeróbia e anaeróbia. As amostras previamente tratadas foram filtradas duas vezes em filtro semiqualitativo antes de serem submetidas aos testes ecotoxicológicos. As bactérias liofilizadas utilizadas nos ensaios foram obtidas da SDI e armazenadas à temperatura de $-20^{\circ} \mathrm{C}$.

Os testes foram realizados de acordo com o protocolo estabelecido pelo software (MICROTOX ' Omni Software, versão 4.1) do equipamento MICROTOXं, Modelo 500 Analyzer. Alterações na luminescência dos organismos foram medidas após $30 \mathrm{minu}$ tos de exposição ao contaminante. As análises ocorreram a partir de nove diluições e um controle, que continha apenas a bactéria em meio salino (solução de ajuste osmótico). As diluições citadas foram realizadas em série, em proporção de 1:2 a partir da amostra original e por meio de uma solução de diluição. Menciona-se que a amostra mais concentrada permaneceu com concentração igual a $81,9 \%$ da original. A toxicidade aguda $\left(\mathrm{EC}_{50}\right)$ foi determinada a partir de medições da luminescência da bactéria nos tempos 5,15 e 30 minutos.

\section{RESULTADOS E DISCUSSÃO}

\section{Ensaios de biodegradabilidade aeróbia e anaeróbia}

Na Tabela 3 são apresentados os resultados obtidos durante o processo de biodegradabilidade aeróbia e anaeróbia por meio da determinação do COT.

Observou-se remoção de aproximadamente 85\% de COT nos reatores. Essa redução de matéria orgânica, no entanto, está relacionada à remoção de glicose, que é facilmente biodegradável. Uma série de estudos têm demonstrado que a maioria dos antibióticos não é biodegradável sob condições aeróbias de tratamento (CRUZ et al., 2012; LI et al., 2008). Esses resultados sugerem que situações semelhantes devem acontecer em ETEs, locais em que o tratamento biológico é empregado e em que são verificadas altas taxas de remoções em termos de demanda química de oxigênio (DQO) e DBO. Nas ETEs, como não são empregadas técnicas para identificação dos compostos recalcitrantes remanescentes no efluente, não é possível verificar quais compostos estão presentes no efluente que será lançado.

Por meio da avaliação da concentração de norfloxacino por UV/Vis (Figuras 2A e 2B), confirma-se a hipótese de que o composto-alvo não foi totalmente biodegradado pelas biomassas

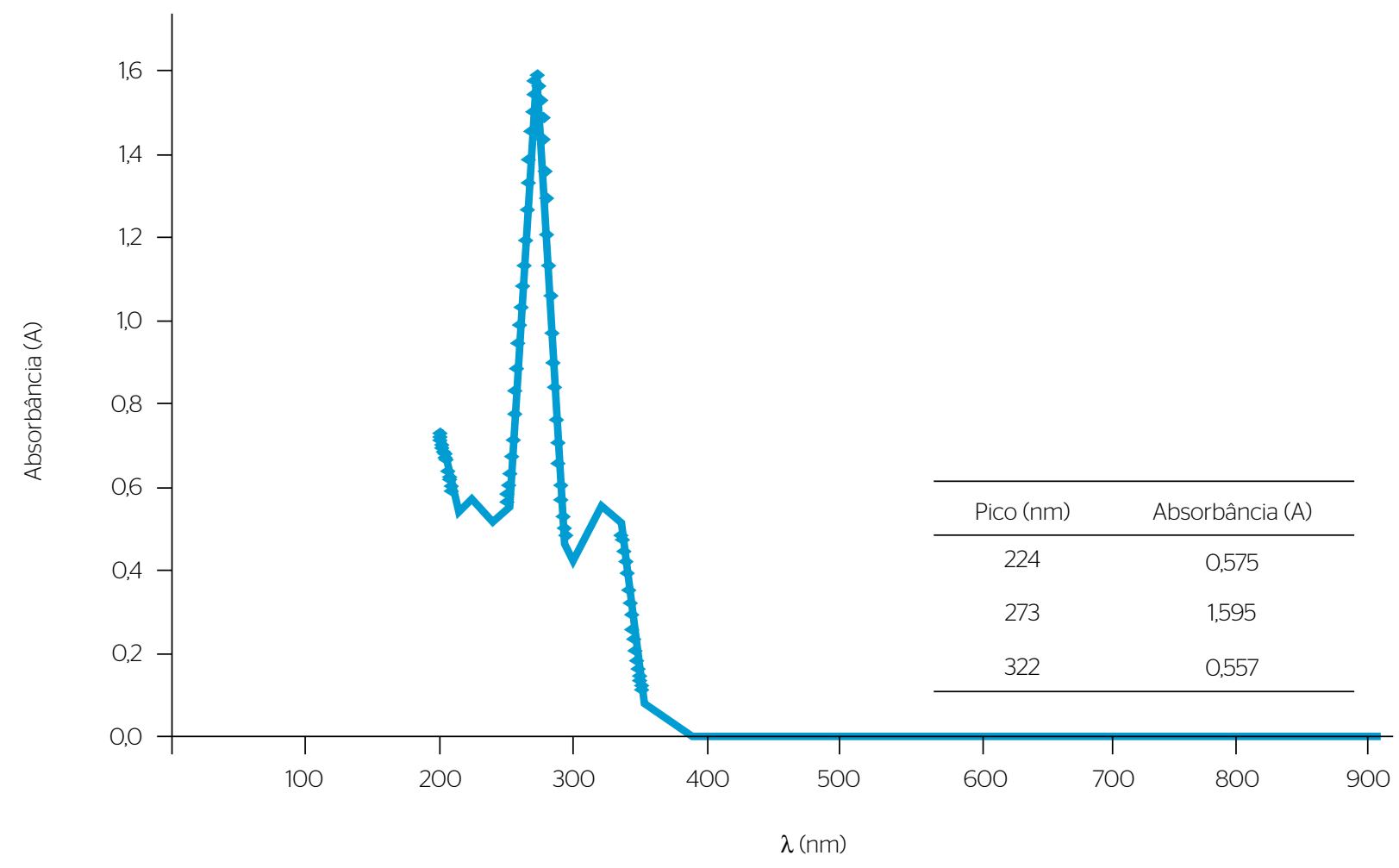

Figura 1 - Espectro de absorção do antibiótico norfloxacino. 
utilizadas, mesmo após o processo de aclimatação. Ressalta-se que, em termos de eficiência de biodegradabilidade, a biomassa proveniente de reatores UASB mostra-se mais eficiente, com $23 \%$ de biodegradação, do que a proveniente de biodigestores anaeróbios, com $18 \%$ de biodegradação, e é ainda mais eficiente que a advinda dos lodos ativados, com 13\% de biodegradação, após 30 dias de ensaio.

Além do processo de biodegradação, outros mecanismos, a exemplo da adsorção, da volatilização e da hidrólise, podem contribuir para a remoção de fármacos durante o processo de tratamento biológico (LI; ZHANG, 2010). Os citados processos podem ser favorecidos ou não a depender da hidrofobicidade que esses compostos apresentam. Tran e Gin (2017) demonstraram que a remoção de alguns fármacos e disruptores endócrinos em sistemas biológicos está altamente relacionada com as características moleculares que tais compostos apresentam. A maior interação desses compostos com o lodo pode favorecer sua remoção devido à possibilidade da adsorção. O coeficiente de partição octanol-água $\left(\mathrm{K}_{\mathrm{OW}}\right)$ diz respeito à hidrofobiciade do composto e pode ser utilizado para avaliar o processo de adsorção de moléculas neutras (LI; ZHANG, 2010). Assim sendo, antibióticos que apresentam $\mathrm{K}_{\mathrm{OW}}<2,5$ são considerados de baixo potencial de adsorção (ROGERS, 1996; TRAN; GIN, 2017), como é o caso do norfloxacino $\left(\mathrm{K}_{\mathrm{OW}}=2,1\right)$. Dessa forma, ainda que haja a contribuição do processo de adsorção para a remoção de norfloxacino, tal fenômeno não seria predominante nem o maior contribuinte para os valores observados. O mecanismo de volatilização também poderia ser desconsiderado neste caso, tendo em vista a baixa constante de Henry que o norfloxacino apresenta $\left(8.60 \mathrm{E}-19 \mathrm{~atm} \cdot \mathrm{m}^{3} \cdot \mathrm{mol}^{-1}\right)$, o alto peso molecular $\left(319.331 \mathrm{~g} \cdot \mathrm{mol}^{-1}\right)$ e a presença de grupos polares em sua estrutura (LI; ZHANG, 2010).

As análises laboratoriais evidenciaram, ainda, aumento na concentração de norfloxacino nos reatores em que se utilizou biomassa aclimatada em comparação com aqueles em que a biomassa não passou pelo processo de aclimatação. Para os reatores que

Tabela 3 - Monitoramento, por meio de carbono orgânico total, da biodegradabilidade aeróbia e anaeróbia do antibiótico norfloxacino com e sem aclimatação da biomassa.

\begin{tabular}{l|c|c|c} 
Tratamento & $\begin{array}{c}\text { COT } \\
\text { Inicial }\end{array}$ & $\begin{array}{c}\text { COT } \\
\text { Final }\end{array}$ & \% Degradação \\
\hline Biodigestor anaeróbio & 99,8 & 15,2 & 84,8 \\
\hline Biodigestor anaeróbio aclimatado & 133,6 & 17,6 & 86,8 \\
\hline UASB & 128,2 & 15,0 & 88,3 \\
\hline UASB aclimatado & 175,3 & 18,5 & 89,4 \\
\hline Lodos ativados & 90,4 & 14,8 & 83,7 \\
\hline Lodos ativados aclimatado & 104,5 & 11,1 & 89,4 \\
\hline
\end{tabular}

COT: carbono orgânico total; UASB: upflow anaerobic sludge blanket. continham biomassa proveniente dos processos com lodos ativados e biodigestores anaeróbios, foram observados acréscimos de 36 e 32\%, respectivamente, na concentração do antibiótico. Para os reatores com biomassa advinda dos reatores UASB, observou-se redução na eficiência do tratamento de 23 para 10\%. Esses resultados foram confirmados por meio do monitoramento de reatores brancos (Figura 2C), em que a presença de norfloxacino é exclusivamente advinda da absorção prévia do antibiótico pelas bactérias, no processo de aclimatação, e liberado por lise celular. Esses reatores foram montados exclusivamente com solução de nutrientes, glicose e biomassa aclimatada.

Esses resultados sugerem que uma parcela do fármaco, já previamente absorvido durante a etapa de aclimatação das bactérias, é liberada por meio da lise celular no meio reacional após a diminuição da concentração de carbono orgânico disponível. Em função do disposto, supõe-se que, em períodos com pouca disponibilidade de matéria orgânica, ocorre lise celular e parte do norfloxacino assimilado anteriormente passa a ser liberada para o meio reacional. Resultados semelhantes foram encontrados por Zhang e Li (2018), que observaram aumento da concentração de fluoroquinolonas após lise celular de lodo utilizado como pré-tratamento de efluentes contendo uma mistura de fármacos. Observa-se, ainda, que as bactérias advindas dos reatores com lodos ativados, se comparadas às advindas dos demais reatores, liberam maior quantidade de norfloxacino no meio reacional, sugerindo menor capacidade de degradação do fármaco por essas bactérias. Cruz et al. (2012) também demonstraram a natureza refratária dessa fluorquinolona por meio de trabalho em que o norfloxacino foi encontrado após tratamento biológico com lodos ativados em uma ETE na Suíça.

\section{Ensaios ecotoxicológicos}

As análises ecotoxicológicas realizadas demonstraram que o norfloxacino a $15 \mathrm{mg} \cdot \mathrm{L}^{-1}$ é tóxico, com o $\mathrm{EC}_{50}$ de $26,25 \%$ em 30 minutos de exposição (Figura 3A). O valor encontrado de $\mathrm{EC}_{50}$ corresponde, portanto, à concentração de $3,9 \mathrm{mg} \cdot \mathrm{L}^{-1}$. Esse valor difere de estudos anteriores (BACKHAUS; SCHOLZE; GRIMME, 2000), realizados em intervalo de tempo diferente, que apontam a toxicidade do fármaco para o mesmo organismo, Aliivibrio fischeri, como igual a $22 \mu \mathrm{g} \cdot \mathrm{L}^{-1}$ em teste com tempo de exposição de 24 horas, fato já esperado devido a um maior tempo de exposição dos organismos ao fármaco. Estudos com as algas P. subcapitata e Chrorella vulgaris apontam $\mathrm{EC}_{50}$ do norfloxacino de $16,6 \mathrm{e} 10,4 \mathrm{mg} \cdot \mathrm{L}^{-1}$, respectivamente (EGUCHI et al., 2004).

Nos testes de biodegradabilidade realizados com biomassa provenientes dos reatores UASB - tanto com bactérias aclimatadas quanto com bactérias não aclimatas - não foi detectada toxicidade. 
A

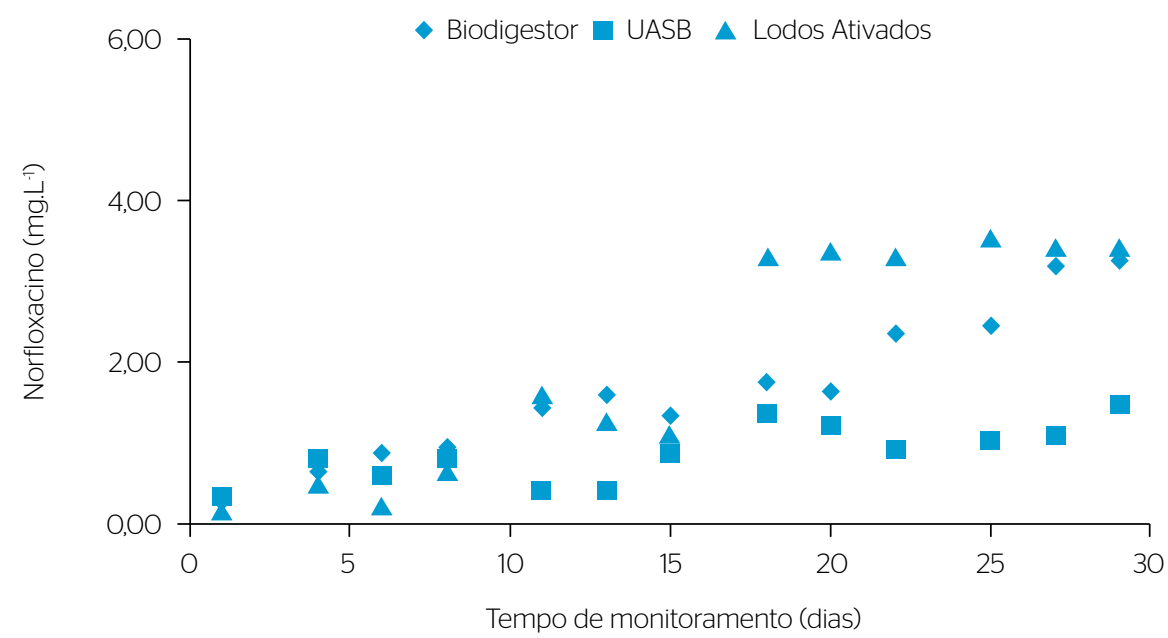

B

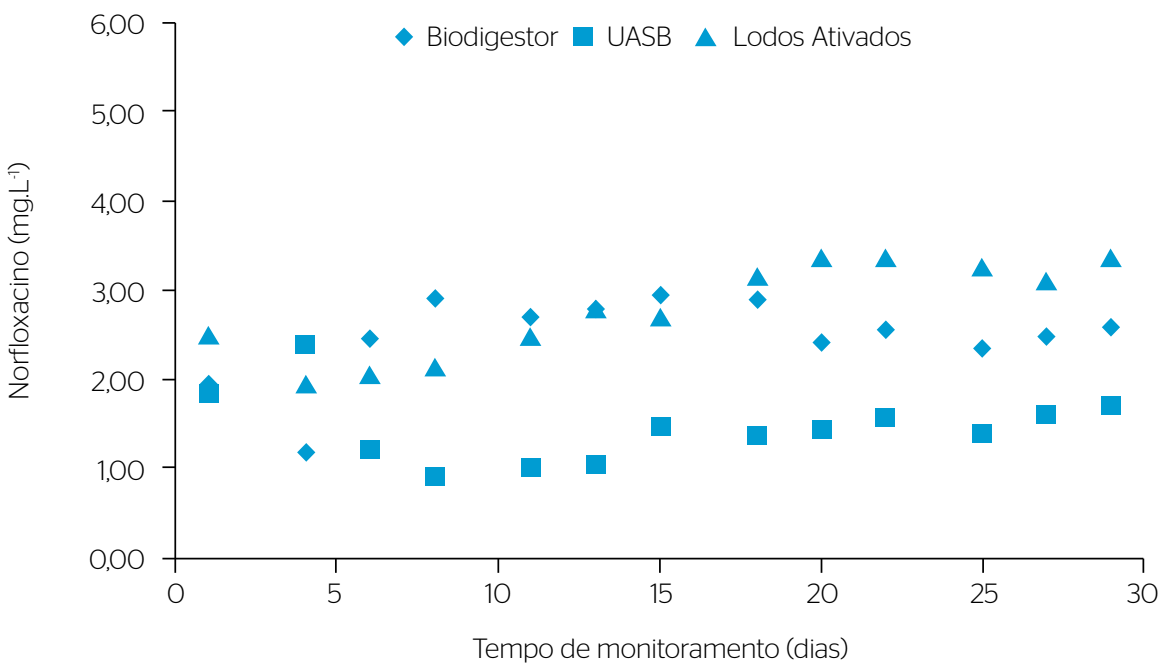

C

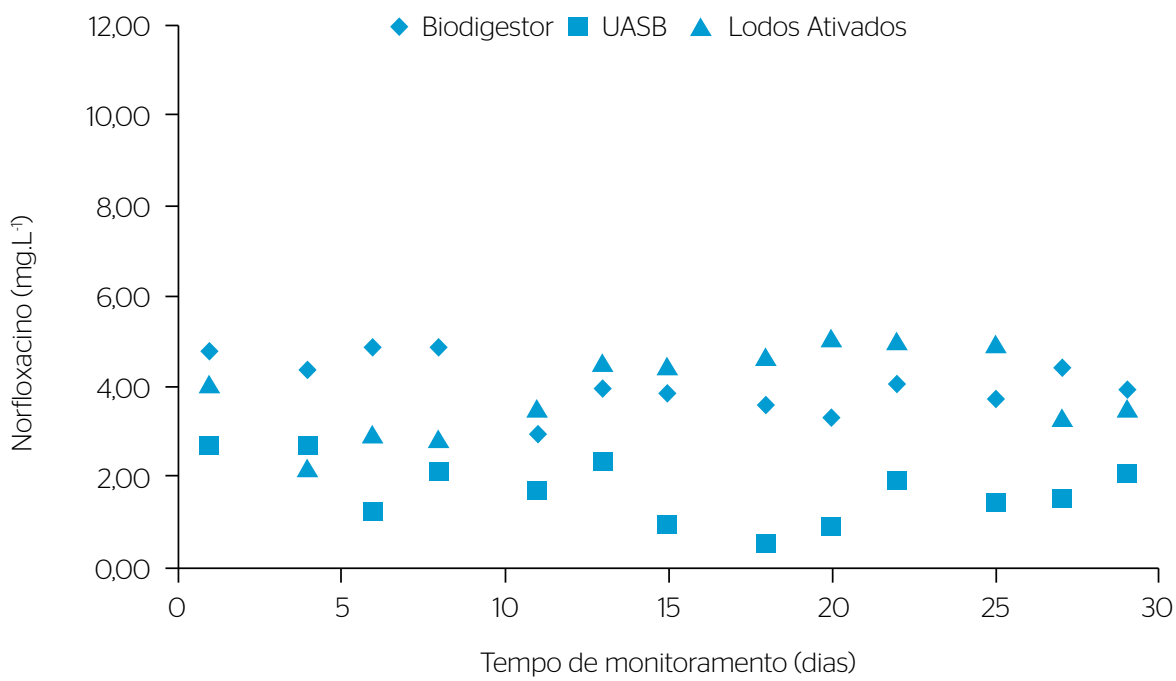

UASB: upflow anaerobic sludge blanket.

Figura 2 - Monitoramento, por meio de UV/VIS, da concentração do antibiótico norfloxacino nos reatores (A) Controle (inoculados com biomassa aclimatada); (B) inoculados com biomassa aclimatada; (C) inoculados com biomassa não aclimatada. 
Em todos os testes, incluindo o proveniente do controle (glicose), foi detectada a hormesis. Esse resultado, provavelmente, justifica-se pelo melhor desempenho dos microrganismos presentes na biomassa do reator UASB. Ressalta-se que a detecção da hormesis não é sinal de que o contaminante seja benéfico ao organismo, ao contrário, pode
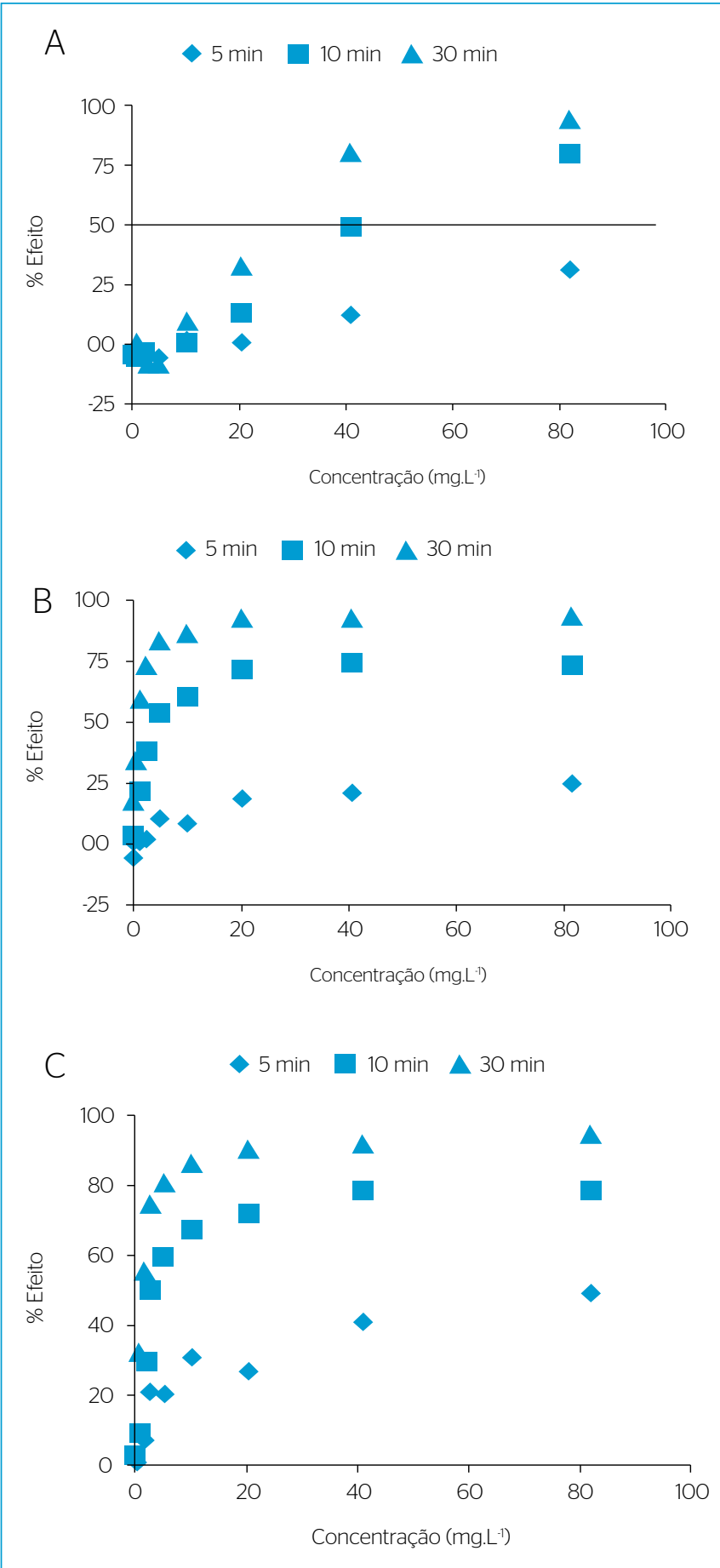

Figura 3 - Porcentagem de efeito (redução de luminosidade) em função da concentração de norfloxacino nos tempos 5, 15 e 30 minutos. (A) Solução inicial; (B) reator branco com lodos ativados aclimatado; (C) reator com lodos ativados sem aclimatação. tratar-se de contaminante que se apresenta tóxico em testes de toxicidade crônica ou em maior concentração em testes de toxicidade aguda (CALABRESE, 2008).

Já nos testes realizados com biomassa proveniente dos biodigestores anaeróbios houve indício de toxicidade nos efluentes dos reatores. Isto é, o meio reacional não estava tóxico $\left(\mathrm{EC}_{50}>81,9 \%\right)$, mas houve efeito de inibição da luz sobre as bactérias. Nesse caso, os resultados são expressos em maior porcentagem de efeito, o que significa maior efeito de inibição de luz detectada. No efluente do reator com biomassa sem aclimatação, o maior efeito de inibição de luz observado foi de $12,99 \%$ em 30 minutos. Já no efluente do reator no qual foi realizado o processo de aclimatação da biomassa esse efeito foi de $7,88 \%$ em 30 minutos, menor, portanto, do que o observado na presença de bactérias não aclimatadas, que são, de fato, menos eficientes.

É importante esclarecer que amostras cujo resultado de toxicidade é expresso em maior porcentagem de efeito geralmente são tóxicas em testes de toxicidade aguda mais longos ou, ainda, em testes de toxicidade crônica. Uma série de estudos indica que o fato de uma substância química não produzir efeitos tóxicos sobre organismos aquáticos em testes de toxicidade aguda não indica que ela não seja tóxica para eles, muitas vezes essa constatação é feita por meio de testes de toxicidade crônica (COSTA et al., 2008; MAGALHÃES; FERRÃO FILHO, 2008).

Os resultados encontrados nos efluentes dos reatores com biomassa advinda dos reatores com lodos ativados (Figuras 3B e 3C) foram os mais tóxicos entre os avaliados, evento que pode ser justificado pela menor eficiência desse tratamento no que tange à remoção do norfloxacino, em comparação aos demais. Os resultados de toxicidade dos efluentes dos reatores supracitados elucidam que aqueles derivados dos reatores com biomassa aclimatada apresentam toxicidade mais elevada $\left(\mathrm{EC}_{50(30 \mathrm{~min})} 2,14 \%\right.$ para o reator com norfloxacino e $\mathrm{EC}_{50}$ (30 min) $1,31 \%$ para reator branco) do que os provenientes dos reatores com biomassa não aclimatada $\left(\mathrm{EC}_{50(30 \mathrm{~min})} 25,94 \%\right)$. Essa situação deve-se ao processo de lise celular (já discutido), que fez com que uma concentração adicional de norfloxacino, de origem endógena, fosse acrescentada ao meio reacional após o processo de lise celular, sobretudo no processo de lodos ativados, se comparado aos demais. Outra hipótese possível seria a de que as bactérias provenientes da biomassa aclimatada geram maior quantidade de subprodutos tóxicos durante a degradação do fármaco.

\section{CONCLUSÕES}

O presente estudo avaliou a eficiência de remoção aeróbia e anaeróbia de norfloxacino em condições otimizadas de degradação. Entre as diferentes biomassas utilizadas, a que se mostrou mais eficiente na remoção do citado composto foi a advinda dos reatores UASB, seguida do biodigestor anaeróbio e, por último, dos lodos ativados. 
Evidenciou-se ainda que em todos os reatores a glicose foi preferencialmente consumida em relação ao norfloxacino. Além disso, o aumento na concentração do fármaco nos reatores em que se utilizou a biomassa aclimatada em comparação com aqueles em que a biomassa não foi aclimatada foi associado ao processo de lise celular. Essa conclusão foi respaldada a partir de análise dos mecanismos de remoção do fármaco em questão pelas bactérias decompositoras.

A eliminação da toxicidade foi promovida pela degradação anaeróbia do antibiótico norfloxacino usando tanto a biomassa do reator UASB quanto a do biodigestor anaeróbio. No entanto, com relação à degradação aeróbia, todos os efluentes gerados apresentaram toxicidade, sobretudo os provenientes de reatores com biomassa aclimatada.

\section{AGRADECIMENTOS}

Os autores agradecem ao Departamento de Engenharia Sanitária e Ambiental da Universidade Federal de Minas Gerais (DESA/UFMG), à Pontifícia Universidade Católica de Minas Gerais (PUC Minas), à Coordenação de Aperfeiçoamento de Pessoal de Nível Superior (CAPES), à Fundação Nacional de Saúde (FUNASA) e à Fundação de Amparo à Pesquisa do Estado de Minas Gerais (FAPEMIG).

\section{REFERÊNCIAS}

AMERICAN PUBLIC HEALTH ASSOCIATION (APHA). (2O12) Standard Methods for the Examination of Water and Wastewater. 21. ed. Washington, D.C.: American Public Health Association.

BACKHAUS, T.; SCHOLZE, M.; GRIMME, H. (2000) The single substance and mixture toxicity of quinolones to the bioluminescent bacterium Vibrio fischeri. Aquatic Toxicology, v. 49, n. 1-2, p. 49-61. https://doi.org/10.1016/S0166-445X(99)00069-7

BOTERO-COY, A.M.; MARTÍNEZ-PACHÓN, D.; BOIX, C.; RINCÓN, R.J.; CASTILLO, N.; ARIAS-MARÍN, L.P.; LOSADA, L.M.; TORRES-PALMA, R.; MONCAYO-LASSO, A.; HERNÁNDEZ, F. (2018) An investigation into the occurrence and removal of pharmaceuticals in Colombian wastewater. Science of the Total Environment, v. 642, p. 842-853.

CALABRESE, E. (2008) Hormesis: why it is important to toxicology and toxicologists. Environmental Toxicology Chemistry, v. 27, n. 7, p. 1451-1474. https://doi.org/10.1897/07-541.1

COSTA, C.R.; OLIVI, P.; BOTTA, C.M.R.; ESPINDOLA, E.L.G. (2008) A toxicidade em ambientes aquáticos: discussão e métodos de avaliação. Química Nova, v. 31, n. 7. p. 1820-1830.

CRUZ, N.L.; GIMÉNEZ, J.; ESPLUGAS, S.; GRANDJEAN, D.; ALENCASTRO, L.F.; PULGARÍN, C. (2012) Degradation of 32 emergent contaminants by UV and neutral photo-fenton in domestic wastewater effluent previouslytreated by activated sludge. Water Research, v. 46, n. 6, p. 1947-1957. https://doi. org/10.1016/j.watres.2012.01.014

DINH, Q.T; MOREAU-GUIGON, E.; LABADIE, P.; ALLIOT, F.; TEIL, M.J.; BLANCHARD, M.; CHEVREUIL, M. (2017) Occurrence of antibiotics in rural catchments. Chemosphere, v. 168, p. 483-490. https://doi. org/10.1016/j.chemosphere.2016.10.106

EGUCHI, K.; NAGASE, H.; OZAWA, M.; ENDOH, Y.S.; GOTO, K.; HIRATA, K.; MIYAMOTO, K.; YOSHIMURA, H. (20O4) Evaluation of antimicrobial agents for veterinary use in the ecotoxicity test using microalgae. Chemosphere, v. 57, n. 11, p. 1733-1738. https://doi. org/10.1016/j.chemosphere.2004.07.017

FIELD, J.; SIERRA, R.; LETTING, G. (1988) Ensayos anaerobios. In: SEMINARIO DE DEPURACIÓN DE AGUAS RESIDUALES, 4. Valladolid. Anais...

HIRSCH, R.; TERNES, T.; HABERER, K.; KRATZ, K.L. (1999) Occurrence of antibiotics in the aquatic environment. Science of the Total Environment, v. 225, n. 1-2, p. 109-118. https://doi.org/10.1016/s00489697(98)00337-4

IMS INSTITUTE (IMSI). (2015) The Global Use of Medicines: Outlook Through 2020. 3 p. Disponível em: <https://www.iqvia.com/-/media/ iqvia/pdfs/institute-reports/global-medicines-use-in-2020.pdf> Acesso em: 14 fev. 2019.

LAJEUNESSE, A.; SMYTH, S.A.; BARCLAY, K.; SAUVÉ, S., GAGNON, C. (2012) Distribution of antidepressant residues in wastewater and biosolids following different treatment processes by municipal wastewater treatment plants in Canada. Water Research, v. 46, n. 17, p. 5600-5612. https://doi.org/10.1016/j.watres.2012.07.042

LI, B; ZHANG, T. (2010) Biodegradation and adsorption of antibiotics in the activated sludge process. Environmental Science \& Technology, v. 44, n. 9, p. 3468-3473. https://doi.org/10.1021/ es903490h 
LI, D.; YANG, M.; HU, J.; ZHANG, Y.; CHANG, H.; JIN, F. (2OO8) Determination of penicillin $G$ and its degradation products in a penicillin production wastewater treatment plant and the receiving river. Water Research, v. 42, n. 1-2, p. 307-317. https://doi.org/10.1016/j. watres.2007.07.016

LINDBERG, R.H.; WENNBERG, P.; JOHANSSON, M.I.; TYSKLIND, M.; ANDERSSON, B.A.V. (2005) Screening of human antibiotic substances and determination of weekly mass flows in five sewage treatment plants in Sweden. Environmental Science \& Technology, v. 39, n. 10, p. 3421-3429. https://doi.org/10.1021/ es048143z

LÓPEZ-SERNA, R.; JURADO, A.; VÁZQUEZ-SUÑÉ, E.; CARRERA, J.; PETROVIC, M.; BARCELÓ, D. (2013) Occurrence of 95 pharmaceuticals and transformation products in urban ground waters underlying the metropolis of Barcelona, Spain. Environmental Pollution, v. 174, p. 305-315. https://doi.org/10.1016/j. envpol.2012.11.022

MAGALHÃES, D.P.; FERRÃO FILHO, A.S.F. (2008) A ecotoxicologia como ferramenta para o biomonitoramento de ecossistemas aquáticos. Oecologia Brasiliensis, v. 12, n. 3, p. 355-381.

MIDDLETON, J.H.; SALIERNO, J.D. (2013) Antibiotic resistance in triclosan tolerant fecal coliforms isolated from surface waters near wastewater treatment plant outflows (Morris County, NJ, USA). Ecotoxicology and Environmental Safety, v. 88, p. 79-88. https://doi. org/10.1016/j.ecoenv.2012.10.025

MUTIYAR, P.K.; MITTAL, A.K. (2014) Risk assessment of antibiotic residues in different water matrices in India: Key issues and challenges. Environmental Science and Pollution Research International, v. 21, n. 12, p. 7723-7736. https://doi.org/10.1007/s11356014-2702-5

ORGANIZAÇÃO MUNDIAL DA SAÚDE (OMS). (2000) Overcoming Antibiotic Resistance. World Health Organization Report in Infectious Diseases. Genebra: OMS.

ORGANIZAÇÃO PARA A COOPERAÇÃO E DESENVOLVIMENTO ECONÔMICO (OECD). (1995) Detailed review paper on biodegradability testing environment monograph no 98.

PAPAGEORGIOU, M.; KOSMA, C.; LAMBROPOULOU, D. (2O16) Seasonal occurrence, removal, mass loading and environmental risk assessment of 55 pharmaceuticals and personal care products in a municipal wastewater treatment plant in Central Greece. Science of the Total Environment, v. 543, p. 547-569. https://doi. org/10.1016/j.scitotenv.2015.11.047

ROGERS, H.R. (1996) Sources, behaviour and fate of organic contaminants during sewage treatment and in sewage sludges. Science of the Total Environment, v. 185, n. 1-3, p. 3-26. https://doi. org/10.1016/0048-9697(96)05039-5

SHAH, S.Q.; COLQUHOUN, D.J.; NIKULI, H.L.; SØRUM, H. (2O12) Prevalence of antibiotic resistance genes in the bacterial flora of integrated fish farming environments of Pakistan and Tanzania. Environmental Science Technology, v. 46, n. 16, p. 8672-8679. https://doi.org/10.1021/es3018607

SILVA, M.A.; TESTOLIN, R.C.; GODINHO-CASTRO, A.P.; CORREAA, A.X.; RADETSKI, C.M. (2011) Environmental impact of industrial sludge stabilization/solidification products: Chemical or ecotoxicological hazard evaluation? Journal of Hazardous Materials, v. 192, n. 3, p. 1108-1113. https://doi.org/10.1016/j.jhazmat.2011.06.019

SUN, Q.; LI, M.; MA, C.; CHEN, X.; XIE, X.; YU, C.P. (2O16) Seasonal and spatial variations of PPCP occurrence, removal and mass loading in three wastewater treatment plants located in different urbanization areas in Xiamen, China. Environmental Pollution, v. 208, p. 371-381. https://doi.org/10.1016/j.envpol.2015.10.003

TRAN, N.H.; GIN, K.Y.H. (2017). Occurrence and removal of pharmaceuticals, hormones, personal care products, and endocrine disrupters in a full-scale water reclamation plant. Science of the Total Environment, v. 599-600, p. 1503-1516. https:// doi.org/10.1016/j.scitotenv.2017.05.097

URBANCZYC, H.; AST, J.; HIGGINS, M.; CARSON, J.; DUNLAP, P. (2007) Reclassification of Vibrio fischeri, Vibrio logei, Vibrio salmonicida and Vibrio wodanis as Aliivibrio fischeri gen. nov., comb. nov., Aliivibriologei com. nov., Aliivibrio salmonicida comb. nov. and Aliivibrio wodanis comb. nov. International Journal of Systematic and Evolutionary Microbiology, v. 57, p. 2823-2829. https://doi. org/10.1099/ijs.0.65081-0

ZHANG, X.; LI, R. (2018) Variation of antibiotics in sludge pretreatment and anaerobic digestion processes: Degradation and solid-liquid distribution. Bioresource Technology, v. 255, p. 266272. https://doi.org/10.1016/j.biortech.2018.01.100 